\title{
"Coaching and Peer-Assisted Learning" (C-PAL) - The mental health nursing student experience: A qualitative evaluation
}

\section{Mark Wareing ${ }^{1}$ (I) | Helen Green ${ }^{2}$ Barbara Burden ${ }^{3}$ | Sally Burns ${ }^{4}$ | Mary AR Beckwith ${ }^{5}$ | \\ 2 Fortune Mhlanga ${ }^{6}$ | Bob Mann 6 \\ Barbara Burden

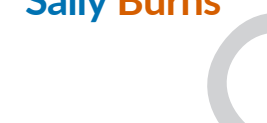

${ }^{1}$ Practice Learning, Uni $\square$ of Bedfordshire, Buckingh 2 re, UK

${ }^{2}$ Education and Development, Oxford Health NHS Foundation Trust, Oxfordshire, UK

${ }^{3}$ School of Healthcare tice, University of Bedfordshire, Buckin 2 hire, UK

${ }^{4}$ Oxford Health NHS Foundation Trust, Oxfordshire, UK

${ }^{5}$ Operating Depart $\bigcirc$ Practice, University of Bedfordaning, Buckinghamshire, UK ${ }^{6}$ Mental $\_$Nursing, University of 3 Bedfordshire, Buckinghamshire, UK

\section{Correspo de}

Mark Wa Practice Learning, University of Bedfordshire, Buckinghamshire, UK.

Email: mark.wareing@beds.ac.uk

\section{Accessible Summary}

What is known on the subject?

- There is increasing demand for clinical placements for prere 2 ation nursing students.

- New models of mentorship have been developed to meet the demand for clinical placements by increasing the number of students within each placement.

- At present there are no published research studies into the effectiveness of team mentorship utilized by prere ation nursing students within in-patient mental health settings.

What does this paper add to existing knowledge?

- This paper reports findings from a study that explored the experiences of mental health students within the social world of their clinical placement, adopting a new approach to practice learning where students support each other's learning.

- Students found their engagement in the pilot project as valuable as being exposed to the new team mentorship model which introduced them to peer-assisted learning.

- The learning that arose from peer-assisted learning within team mentorship appeared to provide learning opportunities that enabled students' to develop greater self-awareness and confidence.

What are the implications for practice?

- Peer-assisted learning where students support the learning of each other, can lead to a wider range of learning opportunities for, as well as between, nursing students.

- In order for students to participate in care and become a "learning team," suitable in-patient mental health wards need to be identified that can support this new approach to the supervision, assessment and support of students.

- The establishment of team mentorship within mental health in-patient settings is dependent on the support provided by practice educators and university link lecturers to nurse mentors and coaches which in turn, determines the quality of the student experience.

\section{Abstract}

Introduction: This paper presents findings from a study that evaluated mental health nursing students' experience of a team mentoring model called Coaching and 
peer-assisted learning (C-PAL). At present there are no published research studies into the effectiveness of team mentorship utilized by nursing students within inpatient mental health settings.

Aim: The study utilized an interpre hethodology where the focus was on individuals in their social world.

Method: Two focus groups were held with fifteen students who had experienced CPAL in four in-patient wards.

Findings: Students' overall experience of piloting C-PAL was positive. Learning opportunities (Theme 3) appeared to be dependent on the quality of peer support (Theme 5) which in turn, enhanced the learner experience and increased the level of student confidence (Theme 6). Less positive experiences included inadequate preparation (Theme 1), poor understanding of the model and competition for learning experiences.

Implications for practice: We tentatively suggest that team mentorship models such as C-PAL may be suitable for acute in-patient mental health settings. The success of C-PAL depends upon the preparation of nursing staff, mentors (Theme 4), coaches and students in relation to role expectations, shift rostering (Theme 2 ) and the implementation of "huddling" to promote opportunistic learning.

KEYWORDS

coaching, C-PAL, mental health nursing students, mentoring, peer-assisted learning

\section{1 | INTRODUCTION}

In order to the challenge of providing sufficient placements for preregis nursing students, new models of mentoring have been developed which provide opportunities for peer-assisted learning whilst introducing mentors and students to the concept of coaching. This paper presents findings from a study to evaluate a model of mentoring developed by an East of England University called "Coaching and Peer-Assisted Learning" (C-PAL).

There are a small range of alternative approaches to one-to-one mentoring that seek to support, supervise and assess nursing students whilst engaging in practice learning within clinical placements. In the USA, "dedicated education units" (DEUs) have been introduced where students are given responsibility to deliver patient care under close collaborative support from education and hospital organizations (Moscato, Miller, \& Logsdon, 2007; Murray \& James, 2012). A key driver for the establishment of DEUs is the reduction in the availability of clinical placements and supervising faculty staff to support a relatively small number of learners within each individual placement (Harris, Keller, \& Hinton, 2018). Practice learning within DEUs may feature "learning dyads" where paired nursing students share decision-making whilst working to care for patients (Mulready-Shick, Kafel, Banister, \& Mylott, 2009). Dyads have been favourably evaluated in respect of patient safety and the enhancement of student confidence (Austria, Baraki, \& Doig, 2013); with one study suggesting that learning dyads instilled teamwork and eased the transition from the classroom to the clinical learning environment (Ruth-Shahd,
2011). Similarly, an Australian study described a "buddying" system that facilitates peer-assisted learning with the support of a nurse mentor who undertakes supervision and assessment of pairs of students (Franklin, 2013; Mallik \& Aylott, 2005). An overriding driver for new approaches to the support of nursing students appears to be the identification of a safe, sustainable approach to the supervision and assessment of increasing numbers of learners supported by partner- $\mathbf{5}$ ships between placement providers and pioher education institutes.

Presently, within the UK all prere tion nursing students studying on approved programmes must be supported and assessed by a mentor, who is registered with the Nursing \& Midwifery Council and has completed an approved mentor preparation programme (NMC, 2008). Recent reviews of nurse education have revealed a shrin ool of mentors set against increasing demand for more prere tion students which suggest that one-to-one mentoring is becoming unsustainable (Lobo, Arthur, \& Lattimer, 2014; RCN 2015). Consequently, initiatives to increase placement capacity through team mentoring models, such as the collaborative learning in practice (CLiP) project (HEEEoE/UEA, 2015), have been introduced in a bid to meet the increasing demand for clinical placements. The need to evaluate new approaches to mentorship is of interest to educators and commissioners have a duty to monitor the quality of 6 clinical placements (HE 16) and healthcare providers who are seeking to enhance their learning cultures (Berwick, 2013). At present there are no published researchendies into the effectiveness of team mentorship utilized by prere $\Omega$ tion nursing students within in-patient mental health settings. 


\section{1 | C-PAL}

The "coaching and peer-assisted learning" (C-PAL) model is very similar to both the CLiP and Amsterdam team mentorship models (RCN, 2015). All three models utilize a team-based approach which enable students to take responsibility for patient care, under the supervision of a coach (a registered nurse) with strategic support provided through a collaborative partnership between the placement provider and the higher education institute. The CPAL model requires students to engage in opportunistic learning that recognizes the value of knowledge within the workplace, the identification of opportunities on offer and what can be created as a result of each opportunity. The role of the coach is to help the student to unlock their potential utilizing a suitable approach such as the GROW model (Whitmore, 2017). This model is introduced to students in the form of a daily learning log and requires learners to set goals they would like to achieve; adjust goals based on what is realistic (as practice enfolds), and identify options and actions to meet their learning goals. Coaches are required to give feedback both to the student and their mentor regarding observed performance which feeds into their practice-based assessment document. The students' responsibility is to collate evidence of their learning using their learning log, to feedback to their mentor who continues to fulfil the role of practice assessor. Additionally, evidence of learning through the use of the log ensures that the coach can assess the degree to which the student has engaged with both the intended curriculum (the learning intentions identified at the commencement of each shift) and the enacted curriculum (what students actually experienced throughout the shift) to promote effective practice learning (Billett, 2014 p. 98,). In the CPAL model, students are expected to work within a group of three students at all times which require students to negotiate and plan their shifts with coaches.

\section{2 | Research question}

This study sought to answer the following research question:

- What are the experiences of students using the C-PAL model within an in-patient mental health setting?

\section{3 | Ethics}

The university's Institute of Healthcare Research granted ethical approval for the study (no. IHREC719). Participation was voluntary and written consent was obtained from all participants who were free to withdraw from the study at any time. Prospective participants were recruited via the university virtual learning site (BREO) where they were able to access electronic copies of the consent form and participant information sheet. Written consent was obtained prior to the commencement of the focus groups.

\section{2 | METHODOLOGY}

The study utilized an interpre 1 hethodology where the primary focus is on the actions of individuals within their social world where the interest focuses on aspects that are unique, individual and qualitative (Crotty, 1998), in an attempt to uncover participants views and perspectives (Gray, 2014).

\section{1 | Method}

All prer 2 ation mental health nursing students who had been exposed to C-PAL within their 9 week non-elect alacements on four pilot wards were invited to take part in a $\mathrm{Fd}$ Group, where discussion was led by a facilitator using a schedule of semi-structured open-ended questions. Participants were asked why they thought C-PAL had been introduced; whether they could recall any particularly vivid learning experiences; what was positive and less positive about C-PAL and to share observations regarding their le support proy by mentors to students (a copy of the Fo schedule 2 vailable from the lead author). One focus group was facilitated by a Senior Lecturer in mental health nursing who was known to the participants of that group, whereas the other focus group was facilitated by a Senior Lecturer from a completely different healthcare programme, who had no previous contact with the participants.

\subsection{Data collection}

The focus groups were of $1 \mathrm{hr} 43 \mathrm{~min}$ and $1 \mathrm{hr} 54 \mathrm{~min}$ durariangespectively ${ }^{\text {up } 1} 1$ comprise $\rightarrow$ eight students (three-fil prised of seven students (two-first-ye $\Omega$ one-ses); 2 year and th third-year students); who had completed placements within one of four i ient mental health wards used to pilot C-PAL. The two Focus ups were audio recorded and transcribed by the research team verbatim (Poland, 1999). Typed transcripts were distributed to the members of the research team. Given the time required to transcribe the focus group recordings and that fact that third-year nursing student participants were about to complete their programme, it was not possible for transcripts to be returned to participants for validation.

\section{3 | Data analysis}

Data analysis of the Focu un transcripts was undertaken using constant comparative analysis (Gray, 2014). The analysis of data comprised of two stages:

Stage 1: Each member of the research team was required to read each transcript through a process of focused reading to identify key words or phrases. Nodes were used to "hold" tentative categories, and readers were asked to capture their initial thoughts and perceptions using memos such as dimensions, comparisons or contrasts. 
Stage 2: The research team met together to generate, through an iterative process of analytical coding and induction, the properties of each code and a theoretical explanation of both transcripts.

The research team used this approach to undertake a thematic analysis of data arising from both focus groups. No computer software was used to analyse or generate themes.

\section{3 | FINDINGS}

We identified six themes from the analysis of the Focus ups transcripts which include preparation, shift patterns, opportunities, mentor involvement, peer support and confidence. This paper presents findings presented in accordance with the Consolidated Criteria for Reporting Qualitative Research (COREQ) guidelines (Tong, Sainsbury, \& Craig, 2007). All data have been anonymized, and pseudonyms have been created in order to present the findings:

\section{1 | Theme 1: Preparation of staff and students}

Whilst Joshua and Billy's wards received some preparation as C-PAL pilot sites, Morgan and Joy's early experiences were less positive as there was a lack of common understanding due to information not being shared with nursing staff:

Initially it was a little awkward in placement when the nursing team said "so you are doing C-PAL; let's do it this way and what do you think of this?" And we did not have any answers because we did not have a full understanding of what it was...

(Morgan, Focu $@$ up 2)

So we had the induction.....which was useful to us.. at least we had an idea of the context and we were able to discuss with mentors and the nursing team and then kind of all of us working from the same page on the issue, rather than "you are now do -PAL". (Billy, Focu 2 up 2).

...I think the manager knew, everything was done, but the rest of the staff did not know anything about it, it was very, very difficult for us in the beginning...

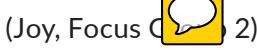

Newton, Billett, Jolly, and Okerby (2011) state 2 t creating an environment which is invitational for nursing students, albeit as peripheral members of the nursing team, is a central focus of novices' learning as they desire to be accepted by their co-workers. It is clear from Morgan and Joshua's experiences that a lack of preparation had an impact on their ability to adapt to the new placement and engage in participatory learning: ...some individual members of the team had different ideas and understandings of the process... there was a clash along with a lack of understanding from the nursing team which caused diffinilty... (Joshua, Focus $@$ ip 2)

In order for practitioners to be successful coaches, they must have knowledge of the role (Haidar, 2007) as alluded to by Morgan who described improvisation resulting from a misunderstanding of expectations. One explanation is that not all nurses serve as mentors or coaches by choice, as the role can sometimes be thrust upon them according to need (Andrews \& Wallis, 1999).

Therefore, ensuring mentors, coaches and students had a common understanding of all roles within C-PAL seemed critical to the extent to which team mentoring was assimilated within nursing teams which in turn, enabled students to engage in participatory learning.

\subsection{Theme 2: Shift patterns}

In odor C-PAL to be implemented based on a mix of firs $\Omega$. ond third-year students, careful rostering of students and a coach needed to be arranged which caused some challenges for Billy and Della:

...there would be a lot of chopping and changing and there was confusion over [whether] we could have one [student] of each year on a shift or amixture of years.

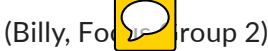

...say there's three students, and the person on shift is ONE of your mentors...however much they try to make it fair...if there are things that come up, learning opportunities, [they] will go to their students and say, "Oh come here, I want to show you so...and that"...the mentor just sort of went back to what I would say "old school" mentoring and just took the student under their wing and said, "This is what we're doing, come along me". (Della, Focus ip 1)

Some students appeared to have been proactive in planning shifts to not only ensure that C-PAL was implemented, but to promote fairness in rostering, as described by Morgan and Tina:

We said let's have a blanket rule about shift pattern; you do early today and then you do late, who does late today probably do first three earlies then the remaining two days of the week you do late so that it is balanced and that solved the problem. (Morgan, Focus 2) 
...my youngest is two years old, so you know, it's just difficult, so you need flexibility so that you're able to swap shifts...there's six of you; you can't say, I want to do early' you can't be prapipe.

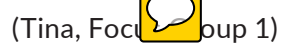

A further challenge was the requirement for nursing students to work a minimum of $40 \%$ of time with their mentor (NMC, 2008) although Billy suggested that greater flexibility in shift planning ensured that C-PAL could still be delivered:

...if C-PAL is rigid...there is no way you can make that $40 \%$ because before you go on that ward the staff have done their rota for one month and you are just coming in and so the first week your mentor might be doing a night and you are on an early, like the mentor was away for three weeks...so all these things were kind of challenging with C-PAL, as the criteria in the PAD says you need to wark 40\%... (Billy, For roup 2)

In order to deliver C-PAL, the rostering of shifts needed to take into account the availability of allocated mentors, the availability of co-mentors; both of whom would be expected to undertake the role of coach for a group of students. Not only did students demonstrate an awareness of the SLAiP standards (NMC, 2008) that stipulate the minimum amount of time students are to work alongside a mentor, but students played an active role in shift rostering to enable C-PAL to be implemented.

Della's comment suggested that how mentors identify learning opportunities for their individual student may clash with the ethos of shared and peer-assisted learning where a student is taken away to either observe or participate in a learning activity. One explanation could be that the mentor may have viewed the presence of their student on the same shift as an opportunity for direct contact that might not have otherwise been afforded, which suggests that the mentor may not have adapted their assessment strategy in the face of C-PAL. Alternatively, a learning opportunity may not always be appropriate for sharing with a group of students.

\section{3 | Theme 3: Opportunities}

Whilst the pilot sites had a range of learning opportunities for students, Precious described some challenges in terms of participation in care that had an impact on the assessment of her skills due to the size of the patient group:

...we only had 20 patients on our ward...yea...so trying to find enough work for you...there are six members of staff on so you have your HCAs and your qualified nurses; then on top of that you have three students. At times the students were out numbering the qualified so it was more like everyone wants to do things, everyone wants to get their skills signed-off regardless of the year and it ended up with some peoploimst clashing... (Precious, Focus G 2)

Sienna, a third-year student, tried to negotiate learning experiences for some of her junior counterparts, but appeared to have met resistance from a qualified nurse:

We tried to get the year ones and twos to coordinate and I was shot down by a staff nurse for suggesting it "they cannot possibly do
(Sienna, Focus Gro.).

Similarly, Tina described occasions where the pace and tempo of the unit did not always afford sufficient learning opportunity:

...all of us needed to have a chance...there'd be the odd, um, manager's meeting or tribunal or whatnot and there's six of you, whereas...where Precious was, it's tribunal every other day...even the nurses, they found it a little bit overwhelming sometimes...there was a times when we're just standing around thinking.

(Tina, Focus 2 1)

Conversely, Wilma, Rob and Penny seemed to develop creativity around the recognition of learning opportunities, not just from new, but existing workplace practices:

...even as a year 3 you will have someone coming to you just privately to get some advice yea, because we are there as role models when you are year 2 , year 3 to the year $1 \mathrm{~s}$ and for me I must say it was a very good opportunity. It is a joy as a second year [or] third year seeing a 1st year student doing very well and being commended by other staff ners.

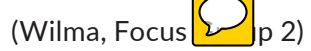

...we have those huddles soon after handover, and just before handover...we say "Guys, let's just have a talk" and you, update, and bring up issues, any problems...say "Guys, you know, do you mind if maybe have the opportunity to..." We could do clinical and do the, ah, physical obs, you know, I mean, so you, you just find ways of doin ings.

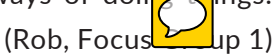

Wenger-Trayner, Fenton-O'Creevy, Hutchinson, Kubiak, and Wenger-Trayner (2015) argue that competence includes a social dimension and is not merely an individual characteristic. Additionally, the achievement of competence is recognizable by members of a community of practice which operates as a regime that pulls and transforms learning as described by Penny and Wilma: 
...it was about grabbing opportunities for learning and more independent learning and learning from each other; but I took it to be the major thing for the year 3 s to have that step-up before they get their first job. (Penny, Focu $@$ up 2)

Some of the opportunities were the same...you could still participate in ward rounds, you could still do handover...I think it was more how you divided it up so you might not be able to do all the stuff that you would like to do; it was a bit of give and take you know you might be able to do the ward round this week, but how about instead of that you write the notes for it...I found that although the same opportunities were there I found that I broadened the way I looked at it by becoming quite creative in what I was doing rather than...I need to get this skill signed-off to do that I need $A B C D$...I was going and talking to a nurse about the medication and [asking] "what did that do?" So although I was not physically handing it out and doing the medication round I was finding otherways to learn...

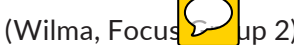

Newton et al. (2011) argues that workplace affordances and the quality of support offered to nursing students and their capacity to engage with the clinical learning environment is critical to the quality of students' experience as described by Morgan:

You know we started to pull up medication charts... we [would] pull up like five or six [charts] and sit down and say "guys...what do you understand by this medication?"...There are different ways of learning and C-PAL makes you look outside the box.

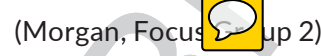

Additionally, Billy described the importance of seeking learning opportunities from within the multidisciplinary team and perceived that patients could also be a valuable source for learning:

My thinking is that most students focus on the registered nurses for opportunities but there are others; the doctors are there, the OTs are there, the patients themselves are there, but we tend to focus more on the registered nurses; this is where the opportunities are. Where we work we grabbed the doctor and wanted to learn about clozapine...Somebody will say "I have got this opportunity with the OT; they are going out, okay you go"...So you look for the onportunity...

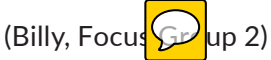

These findings are similar to a study conducted by Martin and Edwards (1998) in which students found learning opportunities were reduced due to the requirement to share them with their peers. Billy, Morgan and Wilma's comments suggest that C-PAL offered students increased opportunity for deeper involvement in learning opportunities through the sharing of ideas and strategies despite being in difficult situations. Peer-assisted learning opportunities have been shown to enable students to increase their confidence (Austria et al., 2013), decrease anxiety and provide a space for clarification of ideas and a rehearsal of skills that need to be achieved (Yates, Cunningham, Moyle, \& Wollin, 1997;).

\section{4 | Theme 4: Mentor involvement}

Setting aside challenges associated with shift working and students being able to work alongside their allocated mentors, Joshua was conscious of how mentors were able to come to a decision regarding performance within practice-based assessment, whilst Morgan described how the daily learning log provided additional evidence for the effectiveness of his practice learning:

...I was not under the wing of my mentor the whole time.... had learnt from everybody; you know they are all mentors in my mind to a certain degl

Unfortunately, our mentors were on nights for a couple of weeks and I did not see mine...The other thing is you have a document and OAR [ongoing achievement record] so depending on the mentor, that individual staff member is dependent on whether they take it as Gospel and whether you have done what is on your sign-off sheet [daily learning log sheet], so that's another thing because it's not necessarily a problem; but it is an issue - you can do something one day and you mentor can see that it has been signed-off, but they may not be happy to sign it because thev wagre not there...

(Joshua, Foc 2 oup 2)

van Woerkom's (2010) Dutch study into the experience of 33 coachees suggested that the existence of mutual trust is critical to the relationship between the coach and coachee as it determines the degree of disclosure from the learner, although differences in personality can be a source of learning. Billy alluded to the quality of the coaching on offer in respect of the protection for poor practice that it afforded him, whereas Morgan reflected on the impact of his mentor's personality:

They still protect you...your mentor or your coach... as a student in case of any error or whatever might happen...but with traditional mentoring you kind of build your relationship with the team through your mentor; you have a stronger relationship with your mentor which transitions to the team, whereas the 
C-PAL approach your relationships are a little bit disjointed with everyone to a point... so I found [it] not necessarily as easy to get to the same level of intimacy as you would have with your mentor... (Billy, Focus $\mathrm{r} \Omega$ )

What I found was that my mentor wanted to know exactly what I had done each day, what I had learnt, how it was useful, what patient I did it with, everything you could imagine; which was fair enough because he was signing my PAD. In that respect having it as detailed as possible on every day with everything that I did...and signed for is more beneficial for me because if I am asked are you sure you did this on this day, I can turn round and say yes...

(Morgan, Focus Gr@)

The theme of "mentor involvement" suggested that C-PAL required the establishment of stronger communication strategies between students and their allocated mentors, particularly when evidence needed to be gathered to support the assessment process. The use of a daily learning log appeared to assist students in capturing evidence of student engagement with learning opportunities and providing reflective feedback, as alluded to by Joshua and Morgan.

\section{5 | Theme 5: Peer support}

"Huddling" where members of the nursing team come together several times a day to discuss their intentions and monitor patient safety (Health Foundation, 2015), seemed to provide a vehicle for peer-assisted learning as suggested by Precious.

...when it was not possible to huddle...we really missed each other...you know, 'we have not huddled!' it was that kind of relationship, we missed you guys from group $A$ and $B$ and it was such a good relationship because in the mornings like if it was group $A$ in the morning immediately after the handover you would be left behind and we would revisit what they said and we would look at the tasks aboag... (Precious, Focus G 2)

This comment aligns with a study conducted by Bates (2016) in which students felt that peer-assisted learning offered an opportunity to collaborate and build professional relationships with peers, as described by Tina:

...it was more...peer learning, where...like as in learning from each other, nurturing, um...leadership skills on all three levels ...what you discover is....we all learn from each other, whether third ye $\rightarrow$ first year, I learnt a lot of stuff from the First redrs because things constantly cha

(Tina, Focus Grou
Billett (2014) describes the process of learning through imitation and mimicry as mimetic learning. Mimesis is shaped by institutional facts, norms and practices; brute facts (which are incontrovertible); personal facts based on an individual's capacities, interests and intentions; and the relationships between these facts. Mimetic learning can be transformative as the consequences can lead to new ways of thinking, doing and innovation for individuals (Billett, 2014 p. 12,). For Precious, Morgan and Joshua, C-PAL was characterized by the formation of relationships and practices that created team working bonds which reflects findings from Ruth-Shahd's (2011) study into learning dyads. This was achieved by learning from, as well as alongside, fellow students:

...what I saw about the C-PAL is it's a commitment that you have to make as a student; to yourself, to your colleagues, to work and the unit...

(Joshua, Focus $\mathrm{Q} \Omega_{2}$ )

Additionally, students perceived the value of peer learning in terms of nurturing one another and working across years of study within their teams as described by Billy, Morgan and Rob:

...you have got the opportunity to learn from two teams. You have got your student team that's the first team and then you have got the wider team which is the MDT. That really is a big opportunitu foy you to learn...

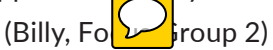

...C-PAL is sweet to be honest because one thing you learn is people management especially because you guys are going to do patient management, you guys are going to do management of colleagues and we have different characters, how do I live with [name] how do I work with [name] and with that you learn how to work collaboratively with colleagues... (Morgan, Fod 2 oup 2)

Rob described the C-PAL learning landscape as having features associated with togetherness and team work that generated support irrespective of the seniority of students, when learners' faced challenges:

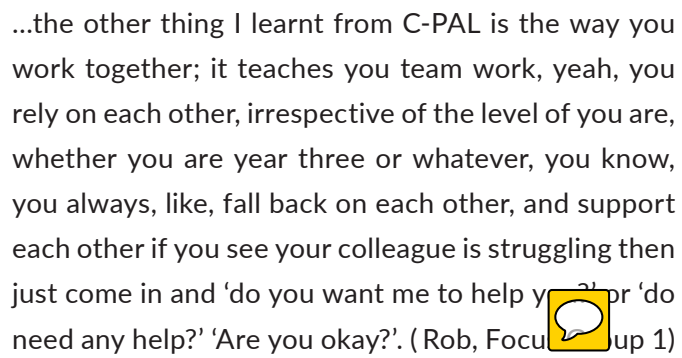

Wenger-Trayner et al. (2015) describe the process whereby learners "find themselves" as being shaped by the landscape of 
practice. This landscape comprises of engagement, concerned with doing, working, talking, using and producing artefacts; imagination, where the image of a learning landscape (working in a hospital as other nurses do) helps orientate and locate us; and alignment, where activity is not only coordinated, direction is received, laws followed and intentions implemented.

\section{6 | Theme 6: Confidence}

Finally, the theme of confidence was described by Wilma in terms of how she saw others grow, whereas Joy and Sienna saw confidence in their ability to become stronger team players. Increased confidence is a significant attribute of peer-assisted learning that has been recognized in several studies (Bates, 2016; Secomb, 2008; Yates et al., 1997). Additionally, C-PAL provided Billy with an opportunity for greater self-awareness which led to deeper insight into the importance of communication within teams:

... this has helped build a lot of confidence for most of the very shy amongst us and they have taken that position you know, as a leader as a year 1 year 2 year 3 and also learn how to listen, sit back and be led by someone who is in a lower year than you; but one beautiful thing about C-PAL is that it sharnong each other...

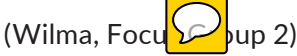

Jarvis (2009) describes the development of social identity as "becoming" and "being." Becoming is signified when an individual is given an ascribed identity (as a novice nursing student) and an achieved identity when graduation and professional registration signifies the new status of being a registered nurse. Like Wilma, Joy saw the value of the C-PAL model in the context of not only the development, but preparation needs of final year students as future qualified nurses:

...for year 3's who are preparing for the 'real life', rather than having your mentor [there] all the time it is about being a team player...how you work with people...it is about leadership, deleartion. (Joy, Focus $@$ p 2)

... I think I have grown more confidence in the last four weeks...I am running the shift, I am working with the team and I feel more comfortable...

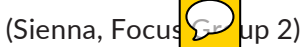

Webster-Wright (2010) asserts that professionals develop a social construction of the self by forming opinions within a public arena where personal views become stabilized over time. The creation of an authentic professional "self" occurs when learners identify what is important to both know and do; within professional contexts, using conversation with others which is external, and through an internal dialogue to create authentic professionalism. Billy alluded to the process by which professionalism and professional identity creation was fostered:

...it gives you confidence, the confidence to do things on your own and work within your team as well...I have improved as a team player I have improved working with different people and understanding peoples' different needs and try to accommodate it in a team... so yes; working as a team, leaderships skills, delegation skills, it is something that I have asquired from C-PAL. (Billy, Foc $@$ oup 2)

Sienna and Billy described how their experience of C-PAL afforded greater confidence through enhanced self-awareness:

C-PAL does make you look at yourself. I discovered a lot about myself in those nine weeks, even the way I talk, how I would talk with you guys in class is obviously completely different. I found out a lot about myself as a positive, even though some of those realities are not nice to realise about (Sienna, Focus $\sum$ ip 2)

I would say that it is an opportunity to find out who you are...how I can work with the team and how I can communicate. You not only communicate with your colleagues, but you communicate with your team as well and it was something that builds you up because you miss someone who is a strong character and someone who is like me more introverted, but now I can come up and say something...

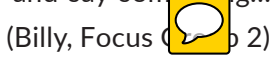

Billett and Henderson (2011) argue that in addition to students learning canonical and occupational knowledge learners need to be self-monitoring of their practice as well as self-directing of their own learning in order to become a professional.

The theme of "confidence" was the strongest finding from both Focus Groups and represented the most significant outcome of the C-PAL pilot for students in terms of the construction of their professional identity as mental health nurses.

\section{4 | DISCUSSION}

The findings from this study suggest that C-PAL provided mental health nursing students within an in-patient setting with a generally positive experience characterized by their strong engagement in opportunistic and participatory learning which enhanced their confidence and leadership skills and led to greater self-awareness. Additionally, students' vivid recollections suggest that engagement 
as part of the pilot project as well as immersion within peer-assisted learning supported by coaches enhanced the learning experience. However, poor preparation of some of the pilot sites had a detrimental effect on the initial learning experiences of participants and is a key finding of this study. Our findings reflect Chan's (2002) study which concluded that continual and open communication between nursing academics, clinical staff and nursing students in the planning of learning experiences sets the social climate of a clinical learning environment. The importance of peer support within C-PAL ensured that peer-assisted learning was delivered, regardless of the year of study of students. We suggest that students were sufficiently inspired to model their learning behaviour in response to the needs of others (Illeris, 2014); in particular fellow students, as well as nursing staff and service users. This finding suggests that team-based approaches such as C-PAL broaden the range of learning relationships available for students in contrast to learning dyads or student "buddying".

It could be argued that C-PAL mirrors the principles of "coproduction" within contemporary mental health where professionals and citizens share power in order to plan and deliver support whilst recognizing that both partners have a vital contribution to make in order to improve quality of life for people and communities (Slay \& Stephens, 2013 pg. 3,). Our study suggests that C-PAL allows learners to be active participants in their own learning and that of others which may have the potential to help mental health nursing students embrace co-production and enhance the service user experience.

\section{5 | LIMITATIONS}

A limitation of this study is that the sample comprised of a mixture of participants of different years of study who had only experienced C-PAL within their individual clinical placement areas. The study did not include the perspectives of mentors, service users and healthcare professionals within the pilot sites, as the experiences of these three groups are currently being evaluated by the placement provider. Interestingly, there did not appear to be any discernible difference between the themes generated from the two focus groups or participants' responses, even though one of the two facilitators had a pre-existing relationship with the participants (Tong et al., 2007). Lastly, participants did not seem to differentiate between the role and practice of coaches as opposed to mentors. This may have been due to the fact that the Focus Group schedule included two questions on the level of support received from coaches and mentors rather than their actual role in the enhancement of practice learning.

\section{6 | CONCLUSION}

The findings relating to the preparation of mental health in-patient areas ahead of the implementation of C-PAL, which includes careful shift rostering and the roles of coaches, mentors and students, suggest that the move away from one-to-one mentoring is a significant cultural change for many nursing staff. For those students expecting to work "under" a mentor, our study revealed that peer-assisted learning can be unsettling. We found that student performance improved in areas such as organizing patient care, managing fellow students, and professional accountability and reflects findings from a study undertaken by Secomb (2008). Indeed, one of the aims of clinical practice for all healthcare students must be to facilitate empowerment so that the student may learn to practice safe patient care independently. Therefore, lecturers and mentors must create situations through facilitation and coaching, in which students may empower themselves. Peer-assisted learning within the mental health in-patient clinical environment appears to do just that.

\section{7 | RELEVANCE STATEMENT}

The findings of this study are of particular interest to academic staff and link lecturers within higher education institutes; practice education, learning environment leads and clinical learning facilitators employed within secondary healthcare environments and mentors and students preparing for engagement with team mentorship or clinically based peer-assisted learning initiatives.

\section{CONFLICT OF INTEREST}

This research did not receive any specific grant from funding agencies in the public, commercial or not-for-profit sectors.

\section{ORCID}

Mark Wareing (iD http://orcid.org/0000-0002-0968-5558

\section{REFERENCES}

Andrews, M., \& Wallis, M. (1999). Mentorship in nursing: A literature review. Journal of Advanced Nursing, 29(1), 201-207. https://doi. org/10.1046/j.1365-2648.1999.00884.x

Austria, M. J., Baraki, K., \& Doig, A. K. (2013). Collaborative learning using nursing student Dyads in the clinical setting. International Journal of Nursing Education Scholarship, 10(1), 1-8.

Bates, D. K. (2016). Perceptions from athletic training students involved in an intentional peer-assisted learning pedagogy. Athletic Training Education Journal, 11(4), 181-188. https://doi.org/10.4085/1104181

Berwick Report (2013) A promise to learn, a commitment to act: Improving the safety of patients in England. At: https://www. gov.uk/government/uploads/system/uploads/attachment_data/ file/226703/Berwick_Report.pdf

Billett, S. (2014). Mimetic Learning at Work: Learning in the Circumstances of Practice. London, UK: Springer.

Billett, S., \& Henderson, A. (Eds.) (2011). Developing Learning Professionals - Integrating Experiences in University and Practice Settings. London, UK: Springer.

Chan, D. S. K. (2002). Associations between student learning outcomes from their clinical placement and their perceptions of the social climate. International Journal of Nursing Studies, 39, 517-524. https:// doi.org/10.1016/S0020-7489(01)00057-8 
Crotty, M. (1998). The Foundations of Social Research: Meaning and perspective in the research process. London, UK: Sage.

Franklin, N. (2013). Clinical supervision in undergraduate nursing students: a review of literature. e-Journal of Business Education \& Scholarship of Teaching, 7(1), 34-42.

Gray, D. E. (2014). Doing Research in the Real World, 3rd ed. London, UK: Sage.

Haidar, E. (2007). Coaching and mentoring nursing students. Nursing management, 14(8), 32-35. https://doi.org/10.7748/nm2007.12.14.8.32. c8241

Harris, J. Y., Keller, S., \& Hinton, E. (2018). Dedicated education units as a clinical rotation for nursing students: A scoping review protocol. JBI Database of Systematic Reviews and Implementation Reports, 16(3), 642-647. https://doi.org/10.11124/JBISRIR-2017-003519

Health Foundation (2015) Using the huddle technique to improve patient safety. At: http://www.health.org.uk/ using-huddle-technique-improve-patient-safety

HEEEoE/UEA (2015) Collaborative learning in practice (CLiP) - evaluation report, Health Education England East of England Locality Office \& University of East Anglia. At: https://www.hee.nhs.uk/ sites/default/files/documents/CLiP\%20evaluation\%20Final.pdf

Illeris, K. (2014). Transformative Learning and Identity. London, UK: Routledge.

Jarvis, P. (2009). Learning to be a person in society. London, UK: Routledge. Lobo, C., Arthur, A., \& Lattimer, V. (2014) Collaborative Learning in Practice (CLiP) for preregistration nursing students: A background paper for delegates attending the CLiP conference, Thursday 18th September, University of East Anglia.

Mallik, M., \& Aylott, E. (2005). Facilitating practice learning in preregistration nursing programmes: A comparative review of the Bournemouth Collaborative Model and Australian models. Nurse Education in Practice, 5(3), 152-160. https://doi.org/10.1016/j.nepr.2004.08.001

Martin, M., \& Edwards, L. (1998). Peer learning on field work placements. British Journal of Occupational Therapy, 61, 249-252. https://doi. org/10.1177/030802269806100603

Moscato, S. R., Miller, J., \& Logsdon, K. (2007). Dedicated Education Unit: An innovative clinical partner education model. Nursing Outlook, 55(1), 31-37. https://doi.org/10.1016/j.outlook.2006.11.001

Mulready-Shick, J., Kafel, K. W., Banister, G., \& Mylott, L. (2009). Enhancing quality and safety competency development at the unit level: An initial evaluation of student learning and clinical teaching on dedicated education units. Journal of Nursing Education, 48(12), 716-719. https://doi.org/10.3928/01484834-20091113-11

Murray, T. A., \& James, D. C. (2012). Evaluation of an academic service partnership using a strategic alliance framework. Nursing Outlook, 60(4), 17-22. https://doi.org/10.1016/j.outlook.2011.10.004

Newton, J. M., Billett, S., Jolly, B., \& Okerby, C. (2011). Chapter 3 Preparing Nurses and Engaging Preceptors. In S. Billett, \& A. Henderson (Eds.), Developing Learning Professionals - Integrating Experiences in University and Practice Settings. London, UK: Springer.

NMC (2008) Standards to support learning and assessment in practice, London, Nursing \& Midwifery Council. At: https://www.nmc.org.uk/standards/additional-standards/ standards-to-support-learning-and-assessment-in-practice/

Poland, B. D. (1999). Transcription quality as an aspect of rigor in qualitative research. In A. Bryan, \& R. G. Burgess (Eds.), Qualitative Research, Vol. III $O$ ton, UK: Sage.

RCN (201 2 ality with Compassion: the future of nurse education report of the Willis Commission. At: https://www.nursingtimes.net/ download?ac $=1255026$

RCN (2015). RCN Mentorship project 2015: From today's support in practice to tomorrow's vision of excellence. London, UK: Royal College of Nursing.

Ruth-Shahd, L. A. (2011). Student nurse dyads create a community of learning: Proposing a holistic clinical education theory. Journal of Advanced Nursing, 67(11), 2445-2454. https://doi. $\operatorname{org} / 10.1111 / \mathrm{j} .1365-2648.2011 .05690 . x$

Secomb, J. (2008). A systematic review of peer teaching and learning in clinical education. Journal of Clinical Nursing, 17(6), 703-716. https:// doi.org/10.1111/j.1365-2702.2007.01954.x

Slay, J., \& Stephens, L. (2013). Co-production in mental health - a literature review. London: New Economics Foundation.

Tong, A., Sainsbury, P., \& Craig, J. (2007). Consolidated criteria for reporting qualitative research (COREQ): A 32-item checklist for interviews and focus groups. International Journal for Quality in Health Care, 19(6), 349-357. https://doi.org/10.1093/intqhc/mzm042

Webster-Wright, A. (2010). Authentic Professional Learning - Making a Difference Through Learning at Work. London: Springer. https://doi. org/10.1007/978-90-481-3947-7

Wenger-Trayner, E., Fenton-O'Creevy, M., Hutchinson, S., Kubiak, C., \& Wenger-Trayner, B. (2015). Learning in Landscapes of Practice: Boundaries, Identity and Knowledgeability in Practice-Based Learning. London, UK: Routledge.

Whitmore, J. (2017). Coaching for Performance: The Principles and Practice of Coaching and Leadership. London: Nicholas Brealey Publishing.

van Woerkom, M. (2010). Chapter 14 The relationship between Coach and Coachee: A Crucial Factor for Coaching Effectiveness. In S. Billett (Ed.), Learning Through Practice - Models, Traditions, Orientations and Approaches. London, UK: Springer.

Yates, P., Cunningham, J., Moyle, W., \& Wollin, J. (1997). Peer mentorship in clinical education: Outcomes of a pilot programme for firstyear students. Nurse Education Today, 17(6), 508-514. https://doi. org/10.1016/S0260-6917(97)80013-5

How to cite this article: Wareing M, Green $\mathrm{H}$, Burden $\mathrm{B}$, et al. "Coaching and Peer-Assisted Learning" (C-PAL) - The mental health nursing student experience: A qualitative evaluation. J Psychiatr Ment Health Nurs. 2018;00:1-10. https://doi. org/10.1111/jpm.12493 